\title{
Activity Patterns and Age-dependent Changes in Behavior in the Clonal Ant Platythyrea punctata
}

\author{
Clara Hartmann • Julia Haschlar • Jürgen Heinze • \\ Abel Bernadou (i)
}

Received: 22 September 2019 /Revised: 1 September 2020 / Accepted: 13 September 2020 /Published online: 18 September 2020

(C) The Author(s) 2020

\begin{abstract}
Age-based polyethism, wherein young individuals perform tasks within the nest and later transition to outside activities, is common among many social insects. This division of labor ensures the safety of workers with longer residual lifespans, such as brood caring nurses, and exposes only old individuals to increased extrinsic mortality risks. It appears however, that lifespan in workers is also shaped by intrinsic factors, such as senescence. The transition from nurse to forager is accompanied by various physiological and behavioral changes and seems to represent a crucial step in determining the subsequent life history of the individual. Here we investigate the daily activity pattern and detailed division of labor in colonies of the clonal ant Platythyrea punctata to better understand the dynamics of age polyethism in this peculiar species. We found that $P$. punctata colonies were mostly active during the day. At night, few workers were observed out of their nests. Workers showed a decrease in brood care and aggressive behavior over time. With increasing age individuals spent more time outside the nest and were more frequently observed walking. However, the transition to outside tasks did not follow a consistent time pattern in all colonies. Workers transitioning at a younger age
\end{abstract}

Electronic supplementary material The online version of this article (https://doi.org/10.1007/s10905-020-09756-8) contains supplementary material, which is available to authorized users.

C. Hartmann · J. Haschlar · J. Heinze $\cdot$ A. Bernadou $(\bowtie)$ Zoology / Evolutionary Biology, University of Regensburg, Universitätsstraße 31, 93053 Regensburg, Germany e-mail: Abel.Bernadou@ur.de seemed to die earlier than workers that began to forage later in life.

Keywords Division of labor · Colony activity · Age polyethism $\cdot$ Lifespan $\cdot$ Platythyrea punctata

\section{Introduction}

The elaborate division of labor of eusocial insects, such as ants, bees, wasps, and termites, is one important factor responsible for their ecological and evolutionary success (Wilson 1971, 1985; Hölldobler and Wilson 1990). Within a colony, reproduction is allocated to only one or a few highly fertile individuals. Nonreproductive workers perform colony maintenance tasks, such as brood-care, colony defense, and foraging (Oster and Wilson 1978). Non-reproductive division of labor may be associated with variation in body size and morphology, differences in genotype, experience, or social feedback (Jeanson and Weidenmüller 2014). In addition, many eusocial insect species also display temporal or age-based polyethism, wherein workers successively pass through phases of performing specific tasks as they age (Oster and Wilson 1978; Robinson 1992; Beshers and Fewell 2001). Young individuals typically focus on tasks in the nest and switch to working outside when they are older (Wilson 1971; Oster and Wilson 1978). This transition involves considerable behavioral, transcriptomic, and physiological changes, including altered hormone and protein levels, a decline in immunity, and accelerated aging (Robinson 1987; Page and 
Peng 2001; Amdam et al. 2004; Giray et al. 2005; Smith et al. 2011; Bernadou et al. 2015). Most of these changes seem to be reversible to some extent, and the option to accelerate or delay the behavioral development of workers might help colonies to more easily adapt to changes in colony demography and environmental conditions (Robinson 1992). However, young workers forced to forage prematurely and older foragers returning to nursing are often less efficient (Robinson et al. 1992; Toth and Robinson 2005; Amdam et al. 2005; Page and Amdam 2007; Giehr et al. 2017). In any case, the age at the transition from inside to outside tasks represents an important regulator of colony dynamics and performance, and on the individual level it strongly influences residual lifespan of the worker (Sakagami and Fukuda 1968; Guzmán-Novoa et al. 1994; Rueppell et al. 2007, 2008, 2009; Santana Vieira et al. 2010; Kwapich and Tschinkel 2016).

The ponerine ant Platythyrea punctata (Formicidae) is a suitable system for investigations about what proximately underlies division of labor among monomorphic individuals and the consequences of division of labor on lifespan (Bernadou et al. 2015, 2018). In most studied populations of this ant, colonies do not contain mated queens or gamergates (mated workers). Instead, all unmated workers are in principle capable of producing female offspring from unfertilized eggs by thelytokous parthenogenesis (Heinze and Hölldobler 1995; Brunner et al. 2009). Young workers establish rank orders through aggressive behaviors such as antennal boxing and biting (Heinze and Hölldobler 1995; Hartmann et al. 2003). In each colony only one or occasionally a few dominant workers begin to lay eggs, while all other workers refrain from reproduction. Reproductive workers live significantly longer than their coeval non-reproductive nestmates (Hartmann and Heinze 2003). Division of labor among non-reproductive workers appears to follow a typical age-based polyethism (Hartmann and Heinze 2003; Bernadou et al. 2015). Foragers are usually older than nurses but at least some of them are able to revert to nursing and egg laying. This reversal appears to slow down their senescence relative to other individuals of the same age (Bernadou et al. 2015). Beyond these two studies, however, few data are available on task partitioning through the lifespan of $P$. punctata individuals, and detailed information about the pace of behavioral transitions is still lacking.
Though insect societies have been studied for many decades, there is still a lack of primary sociometric data for many species (Tschinkel 1991; Hartmann et al. 2003; Brunner et al. 2009; Kellner et al. 2013). Here, we therefore document in detail the daily activity patterns of $P$. punctata colonies and age-associated behavioral changes in workers. We investigated how chronological age affects task allocation and how life-history components (i.e. lifespan, age of first foraging, and foraging span) interacted among them. In particular, we tested how the transition to foraging affects the residual lifespan of individual workers (GuzmánNovoa et al. 1994; Rueppell et al. 2007, 2008, 2009).

\section{Material and Methods}

Study Species and Colony Maintenance

Colonies of Platythyrea punctata were collected in Puerto Rico in 2012 (PR09: Parcelas Vieques, $18^{\circ} 25^{\prime} 9.01^{\prime \prime N}, 65^{\circ} 49^{\prime} 42.34^{\prime \prime W}$; PR25: Luquillo, $18^{\circ} 22^{\prime} 53.83^{\prime \prime N}, 65^{\circ} 43^{\prime} 41.13^{\prime \prime} \mathrm{W}$; PR42: Yuquyiu, $18^{\circ} 20^{\prime} 48.78^{\prime \prime} \mathrm{N}, 65^{\circ} 43^{\prime} 47.76^{\prime \prime} \mathrm{W}$, see below). Colonies have since been maintained in the laboratory either at room temperature $\left(23-26^{\circ} \mathrm{C}\right.$ with a $12 \mathrm{~h}$ light:dark cycle for the experiment on age-based division of labor, lifespan and its components, see below) or in climate chambers $\left(22-26^{\circ} \mathrm{C}\right.$ with a $12 \mathrm{~h}$ light:dark cycle for the experiment on activity patterns) in plastic boxes ( $\mathrm{L} \mathrm{x} \mathrm{W}$ x H: $20 \mathrm{~cm}$ x $20 \mathrm{~cm}$ x $9 \mathrm{~cm}$ ) with a plaster floor, which was regularly moistened. Chambers dug in the plaster and covered by glass plates and black plastic film served as nests. Colonies were fed with diluted honey, small cockroaches or fruit flies three times per week. Water was provided ad libitum in a plastic tube plugged with cotton wool (Bernadou et al. 2018). Prolonged lab rearing did not seem to have visible effect on colony behavior.

Activity Patterns of Colonies

To determine the activity levels of colonies, we calculated the mean percentage of ants found outside the nests of nine colonies every hour over a four-day period (mean colony size $\left[\mathrm{CI}_{95 \%}\right]: 83.44$ [63.57-103.31] workers). One hour before starting the experiment, colonies were fed with diluted honey, cockroaches or fruit flies, and the plaster was moistened (colonies were fed 
only once over the four-day period). To easily assess the number of ants outside the nest on the pictures, all debris (dead ants and cockroaches / Drosophila carcasses from previous feeding) were removed, the black plastic film covering the nest was replaced by a red one and the water tube was replaced by humidified cotton wool placed in a small Petri dish (the cotton was regularly moistened to provide water ad libitum). Colony activity was recorded with a camera (Panasonic ${ }^{\circledR}$ LUMIX model DMC-FZ1000, autofocus mode) fixed on an adjustable stand and centered $75 \mathrm{~cm}$ above the colony. All experiments started around 12:00 i.e., four hours after temperatures had increased from night to day conditions, and pictures were taken every 20 min over a period of four days ( 3 pictures per hour, 216 pictures in total per colony). At night, photos were taken with an optical flash. For two colonies, we missed one and 36 pictures due to erroneous programming of the camera. For each picture, we counted the number of individuals found outside the nest and calculated, based on colony size, the mean percentage of individuals outside for each hour.

Age-based Division of Labor, Lifespan and its Components

Eight to nine callow workers from the three different colonies (mean colony size $\left[\mathrm{CI}_{95 \%}\right.$ ]; PR09: 201.12 [190.51-211.73]; PR25: 166.5 [164.6-168.4] and PR42: 96.86 [85.45-108.27] workers) were individually marked with Edding® paint markers on the day of hatching. The observations started one to three days after marking (mean $\left[\mathrm{CI}_{95 \%}\right]$ : 1.7 [1.33-2.07] days workers were marked but not observed over the weekend) to allow ants to recover from handling. Subsequently, the location (inside or outside the nest) and the behavior of all marked individuals were recorded by scan sampling (37 types of behavior; Bernadou et al. 2015). The scan sampling sessions were carried out randomly between 09:00 and 20:00 (minimum time interval between two consecutive scans of the same worker: 30 minutes). We observed each ant three times per day and five days per week (from Monday to Friday). After 12 weeks, we recorded only the location of marked individuals three times per day and three days per week (on Monday, Wednesday and Friday) until a worker's death. Data on the location of workers during the first 6 weeks were collected and presented elsewhere (Appendix 2, Bernadou et al. 2015).
For each worker, we calculated three life-history components: lifespan (time from when a worker hatched until its death, in days), age of first foraging (first time a worker was observed outside the nest, in days), and foraging span (first time a worker was observed outside the nest until its death, in days) (Guzmán-Novoa et al. 1994; Becerra-Guzmán et al. 2005; Rueppell et al. 2007).

\section{Statistical Analyses}

Activity Patterns of Colonies The mean activity pattern of colonies per hour was plotted over the four days. The mean percentages of individuals found outside the nest per colony during the day and night periods (light:dark cycles for day 2 and 3 ) or for the entire days 2 and 3 were compared by paired t-tests. Days 1 and 4 were excluded from the statistical analysis as we recorded only 12 hours for each day.

Age-based Division of Labor, Lifespan and its Components To visually asses the behavioral changes with age, the most prominent behavioral acts were grouped into six categories (Bernadou et al. 2015: see ethogram - Appendix 1): brood care (except "lay eggs"), aggression, allogrooming (grooming a nestmate or being groomed), self-directed behaviors ("selfgrooming," "feed on prey or honey," and "drink or chew cotton plug water," Londe et al. 2016), inactivity ("inactivity on brood" and "quiescent") and walking ("walk or move"). Infrequent behaviors were excluded from the analysis. The mean percentage of performing a task per colony was calculated for each week and plotted for the first 12 weeks.

The percentage of time workers were found outside the nest per week was analyzed by a linear mixed model (LME, lmer function, lme4 package: Bates et al. 2015). The factors "weeks" (linear and quadratic terms), "colony" and their interaction were introduced in the model as explanatory variables. We included a linear and a quadratic term to model for linear and nonlinear changes in the time spent outside the nest with age. As we repeatedly observed the same workers over time, we included the term "worker identity" as a random factor.

We tested how life-history components (i.e., lifespan, age of first foraging and foraging span) interacted among them. We built three different Poisson generalized linear models (GLMs) and tested whether the 
factors "colony," "age of first foraging" (or "foraging span"), and their interaction influenced the lifespan (or the foraging span) of individuals. Because of overdispersion, the standard errors were corrected using a quasi-GLM model (Zuur et al. 2009).

Statistical analyses were performed by the software R 3.5.3 (R Development Core Team 2016). The least nonsignificant terms $(P>0.05)$ were successively removed and we compared the nested models by likelihood ratio tests to obtain minimal models. The $P$ values for the final models were obtained by the function Anova from the "car" package (Fox and Weisberg 2011). The assumptions of normality and homoscedasticity were checked by Shapiro-Wilk test of normality and Levene's test for homogeneity of variance respectively. Data were transformed when necessary.

\section{Results}

\section{Activity Patterns of Colonies}

The percentage of workers found outside the nest remained stable and high for two colonies over the whole observation period (mean $\left[\mathrm{CI}_{95 \%}\right]$ percentage of workers found outside the nest over four days: 55.25 [53.69-56.81] and 59.34 [58.25-60.43] \%; Fig. S1). These latter two colonies were therefore excluded from subsequent analysis (Fig. 1 and Fig. S1). For the seven remaining colonies a clear activity pattern was observed: workers were mostly active during day time with a peak activity from 13:00 to 19:00 (Fig. 1). The percentage of workers found outside the nest was significantly higher during day than night times (mean $\left[\mathrm{CI}_{95 \%}\right.$ ] percentage of workers found outside the nest from $08 \mathrm{~h}$ to $20 \mathrm{~h}$ vs. 20 h-08h: 20.91 [15.48-26.34] vs. 12.30 [0.01-24.59] and 28.63 [24.4-32.86] vs. 16.28 [10.46-22.1] for days 2 and 3 respectively; Fig. 1) (paired t-test, $t=3.77, P=$ 0.009 and $t=4.73, P=0.003, N=07$, for days 2 and 3 respectively).

We found also a significant effect of time since the last feeding on the number of workers found outside the nest: colonies allocated more workers outside on day 3 than on day 2 (mean $\left[\mathrm{CI}_{95 \%}\right.$ ] percentage of workers found outside the nest: 16.37 [10.69-22.05] and 21.08 [17-25.16] \% for days 2 and 3 respectively; Fig. 1) (paired t-test day 2 vs. day $3, t=-2.96, P=0.02, N=07$ ).

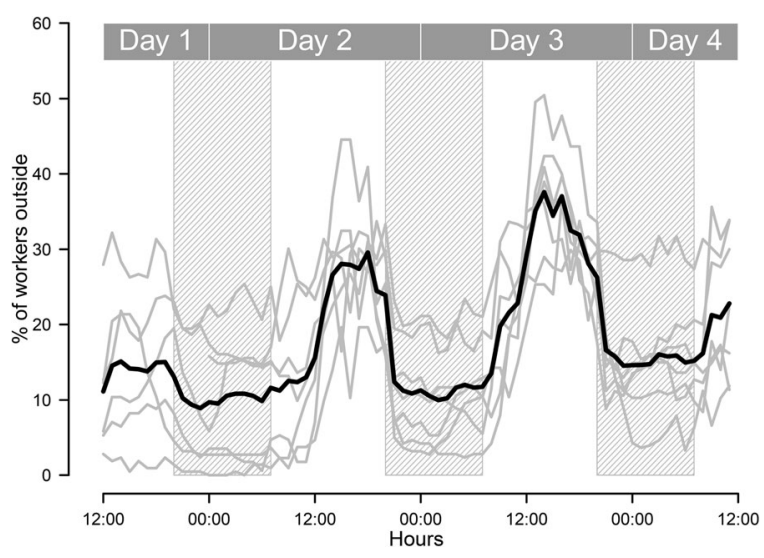

Fig. 1 Percentage of Platythyrea punctata workers found outside their nest per hour over four days. The thin grey lines represent the mean number of workers found outside per colony and per hour ( $N=07$ colonies tested, two additional colonies were discarded; see text and Supplementary material, Figure S1). The bold black line represents the mean number of workers found outside the nest over all colonies and per hour. Colony activity was recorded by taking pictures every $20 \mathrm{~min}$. For each picture, the number of individuals found outside the nest was counted and we calculated, based on colony size, the mean percentage of individuals outside at each hour. The hatched areas represent night periods

Age-based Division of Labor

Two workers died one and eight days after the marking probably due to handling and were therefore excluded from subsequent analyses. Over the 12 weeks of observation, individually marked workers exhibited a typical age-based polyethism (Fig. 2). Among the six behavioral categories defined, we found that the percentages of time spent with brood care, aggression, and walking varied with age. Within all three colonies, the percentage of brood care and aggression decreased consistently with time while that of walking increased (Fig. 2). Though the pattern was less clear for all colonies, selfdirected behaviors, such as self-grooming or eating, decreased until the 5 th to 6 th week and remained nearly constant afterwards. Over the 12 weeks, workers spent much time inactive, but neither for inactivity nor for allogrooming did we observe any clear tendencies (Fig. 2).

Overall, the percentage of time individuals spent outside the nest increased significantly and linearly over time (LME: $X^{2}{ }_{1}=50.47, P<0.001$; Fig. $3 \mathrm{~A}$ ). However, the quadratic effect of week showed a non-significant trend towards predicting the time spent outside the nest (LME: $X^{2}{ }_{1}=2.92, P=0.09$ ). The interaction between weeks and colony (LME: $X^{2}{ }_{2}=13.39, P<0.01$; 
Fig. 2 Mean percentage frequency of Platythyrea punctata workers from three different colonies performing a certain task over a period of 12 weeks (the colors light grey, dark grey and black represent the colonies PR09, PR25 and PR42, respectively). To simplify graphical presentation, we plotted the mean percentage per week per colony
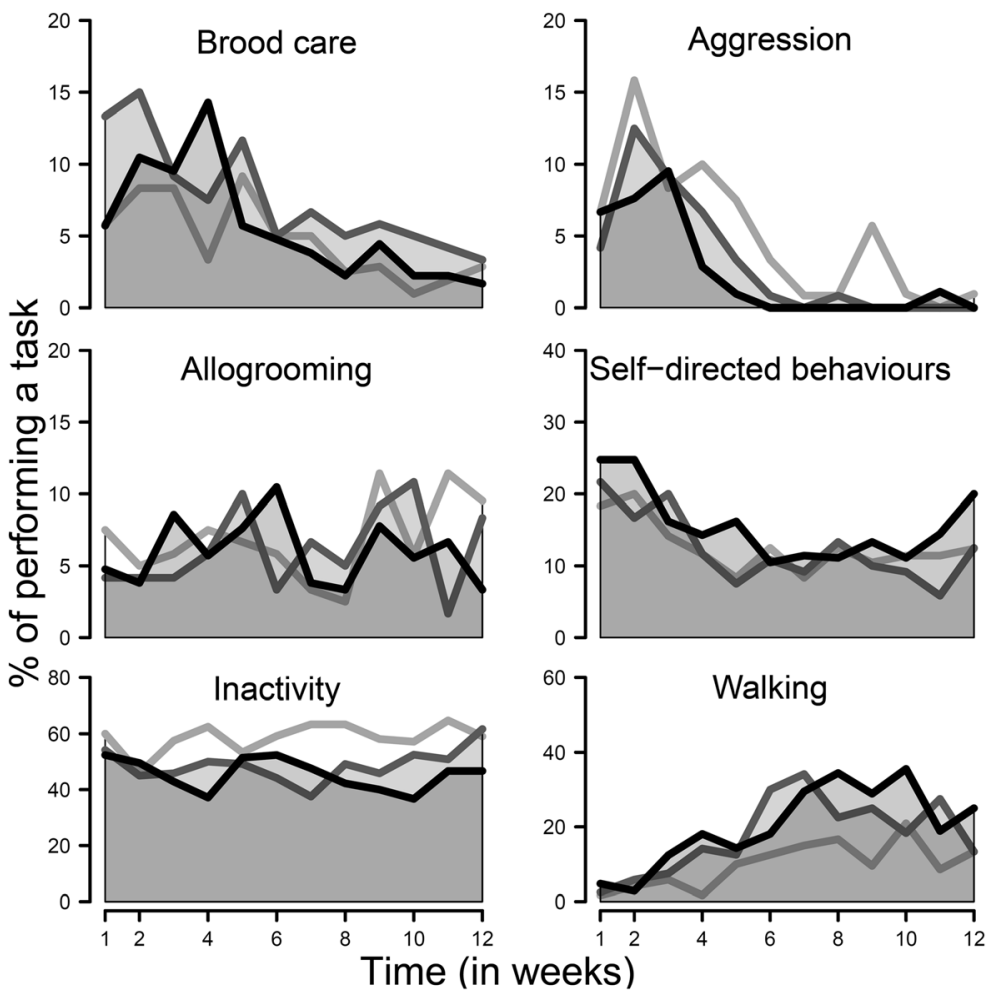

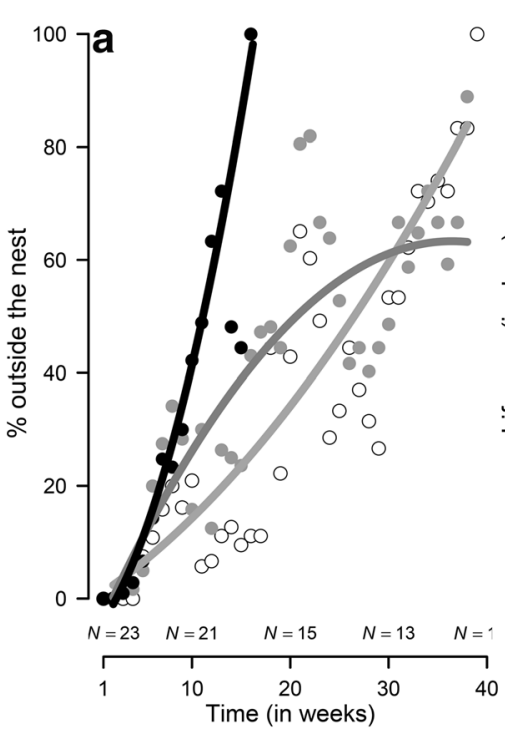

Fig. 3 A Percentage of time per week individual Platythyrea punctata workers were found outside the nest over 40 weeks. Eight to nine individuals from three different colonies (the colors light grey, dark grey and black represent the colonies PR09, PR25 and PR42 respectively) were used. To simplify graphical presentation, we plotted the percentage of time per week per colony with untransformed data. The percentage of time individuals spent outside the nest was significantly influenced by week (LME:

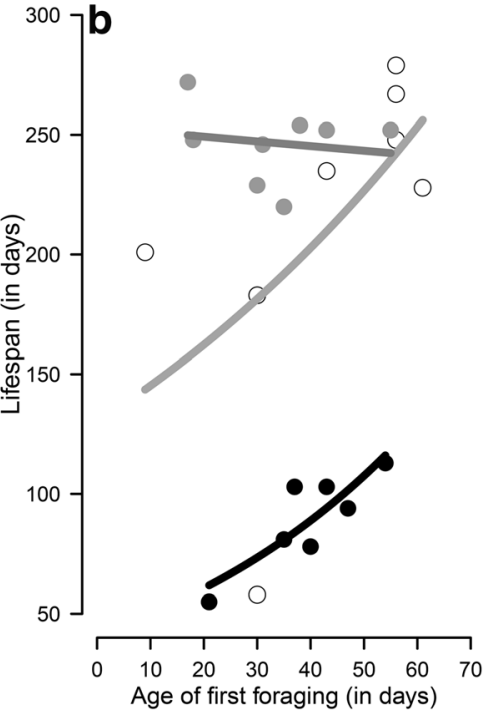

$\left.X_{2}^{2}=50.47, P<0.001\right)$, by the interaction between weeks and colony (LME: $X^{2}{ }_{2}=13.39, P<0.01$ ) and between the quadratic effect of weeks and colony (LME: $X^{2}{ }_{2}=15.68, P<0.001$ ). Models were run using transformed data (see text). B Lifespan of $P$. punctata workers from three different colonies plotted against the age of the first foraging trip. Survival was influenced by colony (GLM: $X_{2}^{2}=74.46, P<0.001$ ) and by the age of the first foraging trip (GLM: $X^{2}{ }_{1}=5.12, P=0.02$ ) 
Fig. 3A) and between the quadratic effect of weeks and colony (LME: $X^{2}{ }_{2}=15.68, P<0.001$; Fig. $3 \mathrm{~A}$ ) were also significant. The factor colony alone did not influence the percentage of time individuals spent outside the nest (LME: $X_{2}^{2}=2.32, P=0.31$ ).

Age of Foraging, Foraging Span and Lifespan

The lifespan of $P$. punctata workers was significantly influenced by the age at which workers were observed foraging for the first time (GLM: $X^{2}{ }_{1}=5.12, P=0.02$; see Fig. 3B) and by colony (GLM: $X^{2}{ }_{2}=74.46$, $P<0.001)$ but not by the interaction between the two factors (GLM: $X_{2}^{2}=3.96, P=0.14$ ).

The total lifespan of workers was significantly associated with foraging span (GLM: $X^{2}{ }_{1}=138.69$, $P<0.001)$, colony origin (GLM: $X^{2}{ }_{2}=15.25$, $P<0.001)$, and their interaction (GLM: $X^{2}{ }_{2}=18.14$, $P<0.001)$.

Finally, we found a significant effect of colony (GLM: $\left.X_{2}^{2}=89.09, P<0.001\right)$ but no effects of age of first foraging (GLM: $X^{2}{ }_{1}=0.53, P=0.47$ ) and the interaction between age of first foraging and colony (GLM: $\left.X_{2}{ }_{2}=2.79, P=0.25\right)$ on the foraging span.

\section{Discussion}

Age-based polyethism has been described for numerous species of social insects (ants, e.g. Calabi et al. 1983, Nakata 1995, Camargo et al. 2007; honey bees, e.g. Michener 1974; wasps, e.g. Ross and Matthews 1991; termites, e.g. Hinze and Leuthold 1999) including the clonal ant Platythyrea punctata (Hartmann and Heinze 2003; Bernadou et al. 2015). In this study we examined in more detail daily activity patterns of colonies and division of non-reproductive labor in $P$. punctata, focusing on the influence of the age of first foraging on residual life span.

Though our colonies have been maintained under laboratory conditions for several years, workers display a clear activity pattern and are mostly active during the day. This is consistent with results on the Malaysian species Platythyrea parallela, which is diurnal with most individuals being active during midday (Ashikin and Hashim 2015). On the contrary, workers of the African species Platythyrea conradti show a peak of activity around dawn (Dejean 2011). Although the activity of our colonies could have been driven by the day:night temperatures of the climatic chambers, this explanation can be partly excluded (Ashikin and Hashim 2015). Colonies allocate more workers outside the nest as the time since the last feeding day increases. Therefore, night temperature does not prevent workers from foraging. Why two colonies did not show a clear daily activity pattern is unclear. A simple explanation might be that these colonies contained more workers and less space in the nest chambers than the other ones (nest chambers were approximately of the same size across the nine colonies), forcing workers to stay outside their nests.

Young workers remained in the nest, where they nursed the brood and behaved aggressively towards their nestmates (Bernadou et al. 2015, 2018). Aggression might be explained by two non-exclusive hypotheses. Most workers in P. punctata can lay eggs; however, reproduction is monopolized by one, occasionally several, dominant workers (Heinze and Hölldobler 1995; Hartmann and Heinze 2003; Bernadou et al. 2015). Therefore (1) young workers may try to aggressively secure a high position in the colony's hierarchy (Monnin and Peeters 1999). In addition, workers may attack rival nestmates that have activated their ovaries despite the presence of a dominant reproductive ("worker policing," Hartmann et al. 2003) and thus stabilize the division of reproductive labor. Like dominance interactions, policing may increase the aggressor's rank in the hierarchy and thus its chance to replace a weakening established reproductive (Brunner et al. 2009). Alternatively, (2) aggressions might reflect intrinsic quality differences between workers and ensure that only the most fecund individuals contribute to a colony's reproduction (Brunner et al. 2009). The link between social status and egg laying capacities or other intrinsic individual qualities, however, remains to be tested. After about two months of age, the frequency of brood care and aggression decreased for most workers while the frequency of walking increased. Young workers that failed to reach a top position in the hierarchy, moved towards the nest entrance and switched from tasks inside the nest to outside tasks (Hartmann and Heinze 2003; Bernadou et al. 2015).

The lifespan of non-reproductive workers was about 200 days (but see colony PR42, around 100 days; Fig. 3), which is consistent with previous estimates (Hartman and Heinze 2003). Workers that started foraging later in life reached a considerably longer total lifespan. Age of first foraging, i.e. the transition from 
nest activities to outside tasks, is a key determinant of worker lifespan in social insects and is likely controlled by several physiological or environmental factors (Neukirch 1982; Guzmán-Novoa et al. 1994; Rueppell et al. 2007, 2008). Our results match previous findings on honey bee workers and confirm the importance of age of first foraging also for the lifespan of ants (e.g. Guzmán-Novoa et al. 1994; Becerra-Guzmán et al. 2005; Rueppell et al. 2007, 2008). The fact, that our colonies were kept in small boxes without predation and other external mortality risks and foraging distances were short, also supports the view that the reduced residual lifespan after the beginning of foraging is not only caused by external mortality risks or wear and tear.

In honey bees, the age of first foraging is negatively correlated with foraging span. This was interpreted as "pre-foraging senescence" (Guzmán-Novoa et al. 1994; Becerra-Guzmán et al. 2005; Rueppell et al. 2007, 2008, 2009). Indeed, intranidal activities in honey bees, such as comb construction, nest maintenance, or brood care, are energetically costly and might result in lipid and protein depletion before foraging onset (Amdam and Omholt 2002; Toth and Robinson 2005; Rueppell et al. 2007). In our study, we could not document a substantial effect of the age of first foraging on foraging span: workers did not appear to trade-off foraging span with days spent inside their nest. The costs of intranidal tasks might be lower in P. punctata than in bees, e.g., brood care activities are probably more limited. We have also shown that $P$. punctata foragers can revert to nursing, egg laying, and regain fat content (Bernadou et al. 2015, 2020). This suggests that workers are more flexible (Bernadou et al. 2015, 2020) and that preforaging senescence can be reverted and is limited in comparison to honey bee workers. For example, reverted nurses in the honey bee do not rebuild their lipid stores (Toth and Robinson 2005).

Worker lifespan and the percentage of time spent outside the nest varied considerably among the colonies. Environmental effects can be excluded as colonies were maintained under controlled conditions. The influence of genetic variation on lifespan and its components, e.g. age of first foraging, has been repeatedly reported in honey bees (see e.g. Calderone and Page 1988; Guzmán-Novoa and Gary 1993; Page and Pankiw 2001; Robinson 2002; Rueppell et al. 2004) and likely occurs also in P. punctata, as different colonies belong to different clones. Colony size may be another factor that indirectly influences the longevity of workers and its components. On the one hand, in smaller colonies, young workers might forage earlier but also have higher workloads, which might negatively impact their survival (Winston and Fergusson 1985; O'Donnell and Jeanne 1992; but see Wolf and Schmid-Hempel 1990; Rueppell et al. 2009). On the other hand, large colony size may favor worker specialization and maximizes colony efficiency (Oster and Wilson 1978; Karsai and Wenzel 1998; Gautrais et al. 2002; Holbrook et al. 2011; but see Dornhaus et al. 2009). Our data support this view: workers from the smallest colony (PR42) started foraging earlier and had a shorter lifespan than workers from the largest colony (PR09). In contrast to colonies PR09 and PR42, the results for colony PR25 are more puzzling: age of first foraging was not associated with total worker longevity. This might be due to the percentage of time workers spent outside the nest, i.e., while it continuously increased in the other two colonies, time spent outside stabilized over time in PR25. It is tempting to speculate that more time spent inside the nest reduced outdoor activities, increased fat content of workers and slowed down senescence (Bernadou et al. 2015, 2020).

In conclusion, we confirmed and documented daily activity pattern of $P$. punctata and age-associated behavioral changes in workers. However, this age-based polyethism as well as lifespan and its components seem to be highly influenced by colony origin. Whether colony size or genetic background controls these variations needs further investigation.

Acknowledgements Open Access funding enabled and organized by Projekt DEAL. The study was supported by DFG grant no. HE1623/37 and BE 6684/1-1 (FOR 2218). We thank Bert Rivera Marchand and Bartosz Walter for their help with obtaining permits for collecting ants in Puerto Rico and Çiğdem Ün for help with behavioral observations.

Open Access This article is licensed under a Creative Commons Attribution 4.0 International License, which permits use, sharing, adaptation, distribution and reproduction in any medium or format, as long as you give appropriate credit to the original author(s) and the source, provide a link to the Creative Commons licence, and indicate if changes were made. The images or other third party material in this article are included in the article's Creative Commons licence, unless indicated otherwise in a credit line to the material. If material is not included in the article's Creative Commons licence and your intended use is not permitted by statutory regulation or exceeds the permitted use, you will need to obtain permission directly from the copyright holder. To view a copy of this licence, visit http://creativecommons.org/licenses/by/4.0/. 


\section{References}

Amdam GV, Omholt SW (2002) The regulatory anatomy of honeybee lifespan. J Theor Biol 216:209-228

Amdam GV, Simões ZL, Hagen A, Norberg K, Schrøder K, Mikkelsen Ø, Kirkwood TB, Omholt SW (2004) Hormonal control of the yolk precursor vitellogenin regulates immune function and longevity in honeybees. Exp Gerontol 39:767773

Amdam GV, Aase ALTO, Seehuus S-C, Fondrk MK, Norberg K, Hartfelder K (2005) Social reversal of immunosenescence in honey bee workers. Exp Gerontol 40:939-947

Ashikin N, Hashim R (2015) Daily activity patterns of Platythyrea parallela in Peninsular Malaysia. Asian Myrmecol 7:145154

Bates D, Mächler M, Bolker B, Walker S (2015) Fitting linear mixed-effects models using lme4. J Stat Softw 67:1-48

Becerra-Guzmán F, Guzmán-Novoa E, Correa-Benítez A, Zozaya-Rubio A (2005) Length of life, age at first foraging and foraging life of africanized and european honey bee (Apis mellifera) workers, during conditions of resource abundance. J Apic Res 44:151-156

Bernadou A, Busch J, Heinze J (2015) Diversity in identity: behavioral flexibility, dominance, and age polyethism in a clonal ant. Behav Ecol Sociobiol 69:1365-1375

Bernadou A, Schrader L, Pable J, Hoffacker E, Meusemann K, Heinze J (2018) Stress and early experience underlie dominance status and division of labour in a clonal insect. Proc $\mathrm{R}$ Soc B Biol Sci 285:20181468. https://doi.org/10.1098 /rspb.2018.1468

Bernadou A, Hoffacker E, Pable J, Heinze J (2020) Lipid content influences division of labour in a clonal ant. J Exp Biol 223: jeb219238. https://doi.org/10.1242/jeb.219238

Beshers SN, Fewell JH (2001) Models of division of labour in social insects. Annu Rev Entomol 46:413-440

Brunner E, Kellner K, Heinze J (2009) Policing and dominance behaviour in the parthenogenetic ant Platythyrea punctata. Anim Behav 78:1427-1431

Calabi P, Traniello JFA, Werner MH (1983) Age polyethism: its occurrence in the ant Pheidole hortensis, and some general considerations. Psyche A J Entomol 90:395-412

Calderone NW, Page RE (1988) Genotypic variability in age polyethism and task specialization in the honey bee, Apis mellifera (Hymenoptera: Apidae). Behav Ecol Sociobiol 22: $17-25$

Camargo RS, Forti LC, Lopes JFS, Andrade APP, Ottati ALT (2007) Age polyethism in the leaf-cutting ant Acromyrmex subterraneus brunneus Forel, 1911 (Hym., Formicidae). J Appl Entomol 131:139-145

Dejean A (2011) Prey capture behavior in an arboreal african ponerine ant. PLoS One 6:e19837. https://doi.org/10.1371 /journal.pone.0019837

Development Core Team R (2016) R: a language and environment for statistical computing. $\mathrm{R}$ foundation for statistical computing, Vienna

Dornhaus A, Holley J-A, Franks NR (2009) Larger colonies do not have more specialized workers in the ant Temnothorax albipennis. Behav Ecol 20:922-929
Fox J, Weisberg S (2011) An R companion to applied regression, 2nd edn. SAGE Publications, Thousand Oaks

Gautrais J, Theraulaz G, Deneubourg JL, Anderson C (2002) Emergent polyethism as a consequence of increased colony size in insect societies. J Theor Biol 215:363-373

Giehr J, Grasse AV, Cremer S, Heinze J, Schrempf A (2017) Ant queens increase their reproductive efforts after pathogen infection. R Soc Open Sci 4:170547

Giray T, Giovanetti M, West-Eberhard MJ (2005) Juvenile hormone, reproduction, and worker behavior in the neotropical social wasp Polistes canadensis. Proc Natl Acad Sci USA 102:3330-3335

Guzmán-Novoa E, Gary NE (1993) Genotypic variability of components of foraging behavior in honey bees (Hymenoptera: Apidae). J Econ Entomol 86:715-721

Guzmán-Novoa E, Page RE, Gary NE (1994) Behavioral and lifehistory components of division of labor in honey bees (Apis mellifera L.). Behav Ecol Sociobiol 34:117-409

Hartmann A, Heinze J (2003) Lay eggs, live longer: division of labor and life span in a clonal ant species. Evolution 57: 2424-2429

Hartmann A, Wantia J, Torres JA, Heinze J (2003) Worker policing without genetic conflicts in a clonal ant. Proc Natl Acad Sci 100:12836-12840

Heinze J, Hölldobler B (1995) Thelytokous parthenogenesis and dominance hierarchies in the ponerine ant Platythyrea punctata. Naturwissenschaften 82:40-41

Hinze B, Leuthold RH (1999) Age related polyethism and activity rhythms in the nest of the termite Macrotermes bellicosus (Isoptera, Termitidae). Insectes Soc 46:392-397

Holbrook CT, Barden PM, Fewell JH (2011) Division of labor increases with colony size in the harvester ant Pogonomyrmex californicus. Behav Ecol 22:960-966

Hölldobler B, Wilson EO (1990) The ants. Belknap Press of Harvard University Press, Cambridge

Jeanson R, Weidenmüller A (2014) Interindividual variability in social insects-proximate causes and ultimate consequences. Biol Rev Camb Philos Soc 89:671-687

Karsai I, Wenzel JW (1998) Productivity, individual-level and colony-level flexibility, and organization of work as consequences of colony size. Proc Natl Acad Sci USA 95:86658669

Kellner K, Seal JN, Heinze J (2013) Sex at the margins: parthenogenesis vs. facultative and obligate sex in a neotropical ant. J Evol Biol 26:108-117

Kwapich CL, Tschinkel WR (2016) Limited flexibility and unusual longevity shape forager allocation in the Florida harvester ant (Pogonomyrmex badius). Behav Ecol Sociobiol 70:1045

Londe S, Molet M, Fisher BL, Monnin T (2016) Reproductive and aggressive behaviours of queen-worker intercastes in the ant Mystrium rogeri and caste evolution. Anim Behav 120:6776

Michener CD (1974) The social behavior of the bees: a comparative study. Belknap Press of Harvard University Press, Cambridge

Monnin T, Peeters C (1999) Dominance hierarchy and reproductive conflicts among subordinates in a monogynous queenless ant. Behav Ecol 10:323-332 
Nakata K (1995) Age polyethism, idiosyncrasy and behavioural flexibility in the queenless ponerine ant, Diacamma sp. J Ethol 13:113-123

Neukirch A (1982) Dependence of the life span of the honeybee (Apis mellifica) upon flight performance and energy consumption. J Comp Physiol 146:35-40

O’Donnell S, Jeanne RL (1992) The effects of colony characteristics on life span and foraging behavior of individual wasps (Polybia occidentalis, Hymenoptera: Vespidae). Insect Soc 39:73-80

Oster GF, Wilson EO (1978) Caste and ecology in the social insects. Princeton University Press, Princeton

Page RE, Amdam GV (2007) The making of a social insect: developmental architectures of social design. BioEssays 29: 334-343

Page R, Pankiw T (2001) Genotype and colony environment affect honeybee (Apis mellifera L.) development and foraging behavior. Behav Ecol Sociobiol 51:87-94

Page RE, Peng CY-S (2001) Aging and development in social insects with emphasis on the honey bee, Apis mellifera L. Exp Gerontol 36:695-711

Robinson GE (1987) Regulation of honey bee age polyethism by juvenile hormone. Behav Ecol Sociobiol 20:329-338

Robinson GE (1992) Regulation of division of labor in insect societies. Annu Rev Entomol 37:637-665

Robinson GE (2002) Genomics and integrative analyses of division of labor in honeybee colonies. Am Nat 160:S160-S172

Robinson GE, Page RE, Strambi C, Strambi A (1992) Colony integration in honey bees:mechanisms of behavioral Reversion. Ethology 90:336-348

Ross KG, Matthews RW (1991) The social biology of wasps. Cornell University Press, Ithaca

Rueppell O, Amdam GV, Page RE, Carey JR (2004) From genes to societies. Sci Aging Knowl Environ 2004:pe5. https://doi. org/10.1126/sageke.2004.5.pe5

Rueppell O, Bachelier C, Fondrk MK, Page RE (2007) Regulation of life history determines lifespan of worker honey bees (Apis mellifera L.). Exp Gerontol 42:1020-1032
Rueppell O, Hunggims E, Tingek S (2008) Association between larger ovaries and pollen foraging in queenless Apis cerana workers wupports the reproductive ground-plan hypothesis of social evolution. J Insect Behav 21:317-321

Rueppell O, Kaftanouglu O, Page RE (2009) Honey bee (Apis mellifera) workers live longer in small than in large colonies. Exp Gerontol 44:447-452

Sakagami SF, Fukuda H (1968) Life tables for worker honeybees. Res Popul Ecol (Kyoto) 10:127-139

Santana Vieira A, Desidério Fernandes W, Fernando AntonialliJunior W (2010) Temporal polyethism, life expectancy, and entropy of workers of the ant Ectatomma vizottoi Almeida, 1987 (Formicidae: Ectatomminae). Acta Ethol 13:23-31

Smith CR, Suarez AV, Tsutsui ND et al (2011) Nutritional asymmetries are related to division of labor in a queenless ant. PLoS One 6:e24011. https://doi.org/10.1371/journal. pone. 0024011

Toth AL, Robinson GE (2005) Worker nutrition and division of labour in honeybees. Anim Behav 69:427-435

Tschinkel WR (1991) Insect sociometry, a field in search of data. Insectes Soc 38:77-82

Wilson EO (1971) The insect societies. Belknap Press of Harvard University Press, Cambridge

Wilson EO (1985) The sociogenesis of insect colonies. Science 228:1489-1495

Winston ML, Fergusson LA (1985) The effect of worker loss on temporal caste structure in colonies of the honeybee (Apis mellifera L.). Can J Zool 63:777-780

Wolf TJ, Schmid-Hempel P (1990) On the integration of individual foraging strategies with colony ergonomics in social insects: nectar-collection in honeybees. Behav Ecol Sociobiol 27:103-111

Zuur AF, Ieno EN, Walker NJ, Saveliev AA, Smith GM (2009) GLM and GAM for Count Data. In: Mixed effects models and extensions in ecology with R. Springer, New York, pp 209-243 